\title{
Improved myocardial function after transmyocardial laser revascularization according to cine magnetic resonance in a porcine model
}

\author{
Olaf M. Mühling, MDa \\ Ying Wang, $\mathrm{MD}^{\mathrm{a}}$ \\ Michael Jerosch-Herold, MD \\ Mary M. Cayton, $\mathrm{RN}^{\mathrm{b}}$ \\ L. Samuel Wann, $M D^{\mathrm{b}}$ \\ Mahmood M. Mirhoseini, MD ${ }^{b}$ \\ Norbert M. Wilke, MD ${ }^{\mathrm{c}}$
}

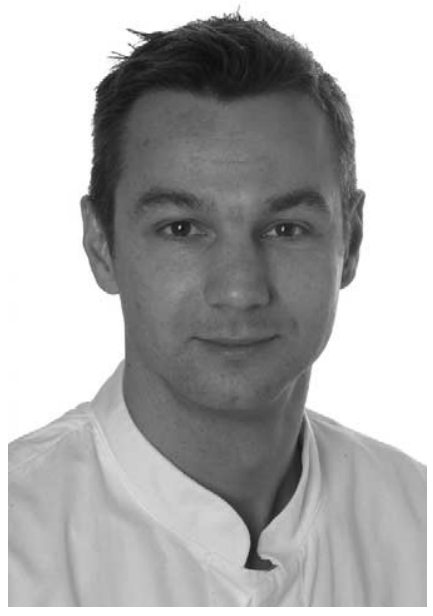

Dr Mühling
From the Cardiovascular MRI Core Lab, Department of Radiology, University of Minnesota Medical School, Minneapolis, Minn, ${ }^{\text {a }}$ the Heart and Lung Institute Wisconsin, Milwaukee, Wis, ${ }^{\text {b }}$ and the Department of Radiology, University of Florida Jacksonville, Jacksonville, Fla. ${ }^{\mathrm{c}}$

O.M. was supported by a grant from the Deutsche Forschungsgemeinschaft (MU 1570/1-1) as a postdoctoral research fellow.

Received for publication Oct 18, 2003; revisions received Nov 28, 2003; accepted for publication Jan 21, 2004.

Address for reprints: Olaf M. Mühling, MD, I. Medical Hospital and Clinics, Grosshadern Campus, University of $\mathrm{Mu}-$ nich, Marchioninistrasse 15, $81377 \mathrm{Mu}$ nich, Germany (E-mail: Olaf.Muehling@ med.uni-muenchen.de).

J Thorac Cardiovasc Surg 2004;128:391-5 $0022-5223 / \$ 30.00$

Copyright (C) 2004 by The American Association for Thoracic Surgery

doi:10.1016/j.jtcvs.2004.01.034
Objective: This study was undertaken to demonstrate that transmyocardial laser revascularization of hypoperfused myocardium improves regional and global myocardial function.

Methods: Cine magnetic resonance imaging was used to monitor regional wall thickening (in millimeters) and cardiac output (in milliliters per kilogram per minute). Cine magnetic resonance imaging was performed before and 8 weeks after transmyocardial laser revascularization was applied to the hypoperfused lateral wall of the left ventricle (target area) in a porcine model $(n=9$, transmyocardial laser revascularization group). A second group of animals was left untreated ( $\mathrm{n}=8$, control group).

Results: Regional wall thickening in the target area improved after transmyocardial laser revascularization $(0.7 \pm 0.3 \mathrm{~mm}$ to $3.7 \pm 1.9 \mathrm{~mm}, P<.02)$ and was significantly higher $(P<.01)$ after transmyocardial laser revascularization than in the control group, in which it did not improve $(0.5 \pm 0.6 \mathrm{~mm}$ to $0.5 \pm 1.2 \mathrm{~mm})$. Accordingly, cardiac output and microsphere-derived myocardial blood flows were significantly higher than in the control group $(P<.01)$, and the amount of triphenyltetrazolium chloride-stained myocardium was lower $(P<.01)$.

Conclusion: Cine magnetic resonance imaging demonstrates improved global and regional myocardial function after transmyocardial laser revascularization in a porcine model.

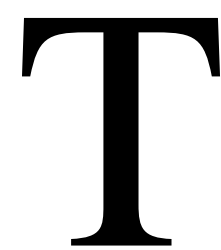

ransmyocardial laser revascularization (TMLR) is approved for patients with debilitating angina and high-risk candidates for a second coronary artery bypass surgery or angioplasty, patients in whom blockages are too diffuse to be treated with bypass alone, and some patients in whom atherosclerosis develops after heart transplantation. Recent clinical trials have demonstrated symptomatic relief for patients with refractory angina after TMLR. ${ }^{1-3}$ However, it has not been established whether this relief of angina is associated with improved regional function. Magnetic resonance imaging may be a more sensitive technique to examine this question. Cine magnetic resonance imaging (CMR) provides high spatial and temporal resolution ${ }^{4}$ and therefore might be suitable to accurately determine even minor changes of myocardial function after TMLR. We hypothesized that TMLR improves regional wall motion and preserves global function because of an improved blood supply. We conducted this study with CMR to follow the changes of left ventricular myocardial function after TMLR in a porcine model. 
End diastole

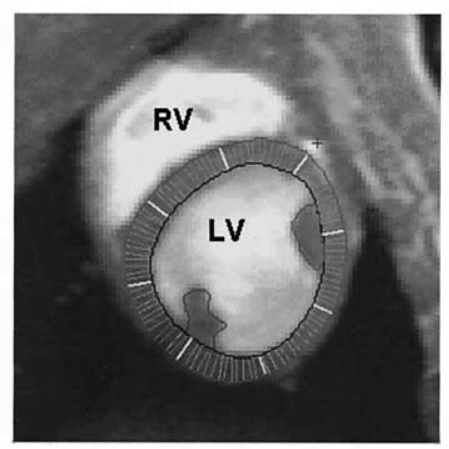

End systole

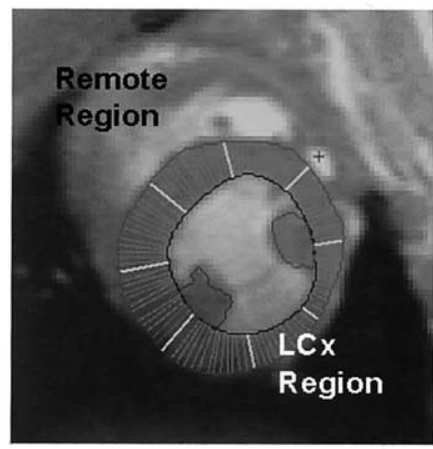

Figure 1. Regional myocardial thickening assessed with the modified centerline method; changes in length of cords between end-diastole and end-systole determine thickening. $R V$, Right ventricular cavity; $L V$, left ventricular cavity; $L C x$, left circumflex artery.

\section{Methods}

All animals received care in compliance with the "Guide for the Care and Use of Laboratory Animals" (http://nap.edu/catalog/ 5140.html). One week after placement of a hollow bead into the left circumflex artery, 17 pigs $(27 \pm 2 \mathrm{~kg}$, range $25-29 \mathrm{~kg}$ ) underwent a first CMR examination. The animals were then randomly assigned to the control group $(n=8)$ or the treatment group $(n=9)$. The latter underwent immediate TMLR, whereas the former underwent a sham operation. Eight weeks after TMLR or sham operation, a second CMR examination was performed in all animals. Microspheres were also injected to determine myocardial blood flow. The animals were then humanely killed, and the hearts were removed for histopathologic assessment.

\section{Bead Placement}

A hollow bead (outer diameter 1.36-1.85 mm; lumen $1 \mathrm{~mm}$, length $4 \mathrm{~mm}$ ) was placed in the left circumflex artery, similar to a previously described protocol. ${ }^{5}$ Before bead placement the diameter of the left circumflex artery was determined and the appropriate bead (1.36-1.85 mm) was implanted, causing an immediate stenosis of approximately $50 \%$ lumen reduction. Intravenous heparin (300 IE/kg; Elkins-Sinn Inc, Cherryhill, NJ) was administered during a period of 7 days in both animal groups. One week after the procedure, a coronary angiogram was performed to document the status (patent or closed) of the bead.

\section{TMLR or Sham Operation}

All animals were sedated with ketamine $(25 \mathrm{mg} / \mathrm{kg}$ Keta Ved; Vedco, Inc, St Joseph, Mo). With sterile technique a left lateral thoracotomy through the fifth intercostal space was performed. A modified high-powered (1000 $\mathrm{W}$ peak, $40 \pm 5 \mathrm{~J}$ pulse energy) carbon dioxide laser (PLC Medical Systems, Franklin, Mass) was used to create $30 \pm 5$ laser channels uniformly distributed over the left ventricular lateral wall. Transmural penetration was confirmed by transesophageal echocardiography. Hemostasis was obtained by manually applied gentle pressure, and the thorax was closed in layers.

\section{Image Acquisition and Analysis}

During image acquisition, left ventricular end-diastolic pressure, aortic pressure, and heart rate were monitored. CMR was performed in a 1.5-T scanner (Siemens Vision; Siemens AG, Erlanger, Germany). A phased-array radiofrequency body coil was used for imaging. Cine imaging was performed with an electrocardiographically gated segmented cine sequence (TR/TE 33/6 ms, flip angle $25^{\circ}$, matrix $87 \times 128$, pixel size $2 \times 1.4 \mathrm{~mm}^{2}$ ) and a slice thickness of $7 \mathrm{~mm}$ without gap. Temporal resolution was 15 frames/beat. The entire heart was covered from base to apex with 8 to 10 short-axis slices, which were defined as the image plane perpendicular to the left ventricular long axis.

Functional parameters were determined in a blinded setting with MASS-software (version 1.0; Leiden University Medical Center, Leiden, The Netherlands). Endocardial and epicardial borders of the left ventricle were defined manually in each ED and ES frame by an observer who was blinded to the status of the animal. A stack of contiguous slices was used to create a 3-dimensional surface rendering of the left ventricular volume to determine cardiac output (in milliliters per minute per kilogram) and ejection fraction (as a percentage). Regional wall thickening was analyzed in the septal (remote) myocardium and in the lateral wall (target region) according to the centerline method. ${ }^{6}$ The circumference of the myocardial short axis was divided in 100 cords aligned perpendicular to the endocardial and epicardial surface (Figure 1). Myocardial thickening was calculated by the difference between end-diastolic and end-systolic lengths of each cord. Reduced thickening in the lateral wall was defined as thickening of $1.9 \mathrm{~mm}$ or less, which is 2 SDs below the thickening of the healthy left ventricular myocardium in a weight-matched control group (myocardial thickening in the lateral wall $3.5 \pm 0.8 \mathrm{~mm}$ and $3.8 \pm 0.7 \mathrm{~mm}$ in the septal wall, unpublished observations). The remote region was defined as the 25 from a total of 100 cords opposing the target region.

\section{Determination of Blood Flow and Histopathology}

Myocardial blood flow (in milliliters per gram per minute) was assessed in the target and remote myocardium (Figure 2). Trans- 
mural myocardial blood flow was determined with radiolobeled microspheres as described earlier, ${ }^{7}$ and endocardial/epicardial blood flow ratios were calculated. The necrotic area was determined by planimetry in 6 to 8 slices of $10-\mathrm{mm}$ thickness according to the double oblique short-axis orientation obtained by CMR. The necrotic tissue was stained with triphenyltetrazolium chloride (TTC). The volume of the necrosis was determined by the average area of the TTC-unstained area at the basal and apical surface of the slice multiplied by the thickness of the slice. In each animal no more than 1 or 2 slices contained unstained myocardium.

\section{Statistics}

Data were analyzed with the SPSS statistical software package (release 10; SPSS Inc, Chicago, Ill). All data are mean \pm SD. Follow-up data within a group and data between groups at a given time point were tested with 1 -factor analysis of variance. Follow-up data between groups were tested with 2-factor (time, group) analysis of variance with repetition.

\section{Results}

One week after bead placement, the angiograms showed decreased and delayed antegrade coronary opacification without substantial collateral filling in all animals. Hemodynamic data and CMR-derived volumetric data are displayed in Table 1. Data for regional wall thickening are displayed in Table 2. At 1 week the number of dysfunctional cords (defining the extend of the ischemic region) between the two groups was not significantly different (TMLR $21 \pm$ 8 , control $17 \pm 4, P=.4$ ). The number of dysfunctional cords decreased significantly in the treated group (6 \pm 6 , $P<.02)$ but not in the control group $(14 \pm 3, P$ not significant) at the 8 week follow-up. The difference between the groups after 8 weeks was significant $(P<.04)$.

Table 3 shows data on myocardial blood flow. Myocardial blood flow in the remote myocardium was significantly higher than in the ischemic zone in both groups. Transmural blood flows in the target and remote regions were significantly higher in the treated animals than in the control group. The endocardial/epicardial blood flow ratio was significantly higher in the treated ischemic region than in the ischemic untreated region of control animals.

At autopsy, all beads in both groups were inspected and found to be closed. TTC-staining revealed "patchy" unstained myocardium in the subendocardial region, indicating minimal necrosis within the target area, in all animals. Planimetric examination of the TTC-stained area demonstrated a significantly higher amount of necrotic tissue in control animals (Table 3 ).

\section{Discussion}

In this study we used CMR to demonstrate changes in myocardial function after TMLR of ischemic myocardium. Both the ischemic and the remote myocardial regions showed regional improvement relative to a control group after TMLR treatment. Accordingly, myocardial blood flow

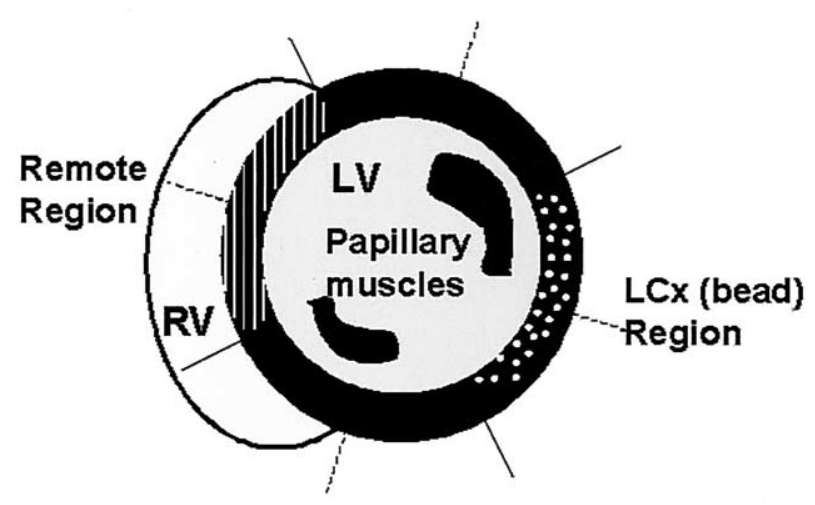

Figure 2. Schematic diagram of ischemic (bead-dependent) and remote myocardial regions in left ventricular short-axis position. $L V$, Left ventricular cavity; $R V$, right ventricular cavity; $L C x$, left circumflex artery.

was increased in the ischemic and remote areas, and the amount of left ventricular necrosis was smaller than in the control group. The regional improvement was paralleled by a preserved global myocardial function in the treated group. In addition, TMLR limited the extension of the necrosis in our model, as indicated by the reduced amount of necrosis and dysfunctional cords in the treated group.

The reduced myocardial function in the remote zone of the untreated control group is consistent with clinical reports by Kramer and colleagues, ${ }^{8}$ who found impaired regional function of the remote myocardium paralleling the reduced function of an opposing infarcted region. Two potential mechanisms could explain our findings in the remote area: reduced coronary flow in the remote area, ${ }^{9}$ as confirmed by our microsphere data, and increased loading and mechanical tethering of the remote region, ${ }^{10}$ represented by a decreased thickening in this area in our control group.

In our study there was improved blood supply after TMLR. The exact mechanism remains controversial and may include angiogenesis. ${ }^{11}$ TMLR-induced angiogenesis has been shown in ischemic ${ }^{11}$ and nonischemic myocardium. ${ }^{12}$ However, the mechanisms of neovascularization after TMLR are not well understood. An inflammatory response, with liberation of cytokines and growth factors and upregulation of receptors, has been proposed as a possible mechanism. There was an increased endocardial/epicardial blood flow ratio in ischemic myocardium in our treated group relative to control animals. Because there was no significant difference in left ventricular end-diastolic pressure between the groups, this diminished blood flow ratio cannot be explained by an increased left ventricular end-diastolic pressure in the untreated group. A reduced amount of recruitable endocardial microvasculature or an impaired ability to dilate because of perivascular fibrosis, combined with a more 
TABLE 1. Catheter-derived hemodynamic variables and volumes determined with CMR

\begin{tabular}{|c|c|c|c|c|}
\hline & \multicolumn{2}{|c|}{1 wk (before TMLR) } & \multicolumn{2}{|c|}{$8 \mathbf{w k}$} \\
\hline & TMLR & Control & TMLR & Control \\
\hline Heart rate (beats/min) & $90 \pm 17$ & $96 \pm 10$ & $94 \pm 12$ & $86 \pm 20$ \\
\hline Cardiac output (mL/[kg $\cdot \min ])$ & $116 \pm 23$ & $122 \pm 20$ & $118 \pm 12$ & $73 \pm 18^{*} \dagger$ \\
\hline Mean aortic pressure $(\mathrm{mm} \mathrm{Hg})$ & $86 \pm 8$ & $90 \pm 6$ & $97 \pm 20$ & $92 \pm 6$ \\
\hline Left ventricular end-diastolic pressure $(\mathrm{mm} \mathrm{Hg})$ & $12 \pm 7$ & $15 \pm 7$ & $13 \pm 2$ & $13 \pm 5$ \\
\hline Ejection fraction $(\%)$ & $56 \pm 9$ & $56 \pm 10$ & $55 \pm 9$ & $55 \pm 6$ \\
\hline
\end{tabular}

Untreated group $\mathrm{n}=6$, treated group $\mathrm{n}=7$.

${ }^{*} P<.01$ within group.

$\dagger P<.01$ between groups.

TABLE 2. Regional myocardial thickening $(\mathrm{mm})$ in the target and remote myocardium

\begin{tabular}{lcccc}
\hline & \multicolumn{2}{c}{ Before TMLR } & & \multicolumn{1}{c}{$\mathbf{8}$ wk after TMLR } \\
\cline { 2 - 5 } & TMLR & Control & TMLR & Control \\
\hline Target myocardium & $0.7 \pm 0.3$ & $0.5 \pm 0.6$ & $3.7 \pm 1.9^{*}$ & $0.5 \pm 1.2 \dagger$ \\
Remote myocardium & $4.9 \pm 0.9$ & $4.7 \pm 0.7$ & $5.7 \pm 1.0$ & $3.7 \pm 1.2 \dagger \ddagger$ \\
\hline
\end{tabular}

${ }^{*} P<.01$ for baseline to follow-up.

$\dagger P<.05$ between groups.

$\ddagger P<.05$ for baseline to follow-up.

TABLE 3. Microsphere-derived regional myocardial blood flows and endomyocardial/epimyocardial blood flow ratios in the target and remote myocardium and percentage necrosis of the left ventricle according to TTC staining in target myocardium after TMLR

\begin{tabular}{|c|c|c|c|c|c|c|}
\hline \multirow[b]{2}{*}{ Group } & \multicolumn{2}{|c|}{ Blood flow $(\mathrm{mL} /[\mathrm{g} \cdot \min ])$} & \multicolumn{2}{|c|}{ Endocardial/epicardial ratio } & \multicolumn{2}{|c|}{ Necrosis of left ventricle (\%) } \\
\hline & TMLR & Control & TMLR & Control & TMLR & Control \\
\hline Target myocardium & $0.6 \pm 0.3^{*}$ & $0.2 \pm 0.1$ & $1.2 \pm 0.1$ & $0.8 \pm 0.4 \dagger$ & $3.7 \pm 1.5^{*}$ & $6.6 \pm 1.6$ \\
\hline Remote myocardium & $1.2 \pm 0.1^{*} \ddagger$ & $0.8 \pm 0.2 \ddagger$ & $1.2 \pm 0.1$ & $1.2 \pm 0.2$ & & \\
\hline
\end{tabular}

${ }^{*} P<.01$ versus control group.

† $P<.05$ versus TMLR group.

$\ddagger P<.01$ versus target myocardium.

extensive TTC-unstained area in the ischemic myocardium of control animal, may explain the decreased endocardial/ epicardial blood flow ratio.

\section{Clinical Implications and Conclusion}

Most clinical trials have demonstrated relief of angina after TMLR. ${ }^{13}$ TMLR, in particular with the Ho:YAG laser and the carbon dioxide laser used in this animal study, has therefore been approved by the Food and Drug Administration. This is in contrast to percutaneous myocardial laser revascularization, which is still considered investigational and has not been approved by the Food and Drug Administration. Not all trials assessed quantitative segmental myocardial function ${ }^{2,3}$ and some used different methods, with variable results regarding an improved outcome after TMLR. $^{1,14}$

The variable results may be explained by less precise quantification of global and segmental function with quali- tative or other quantitative methods. In vivo and in vitro studies have shown that CMR is a valid and reproducible method. ${ }^{15}$ It is dimensionally accurate and needs no geometric assumptions, in contrast to 2-dimensional methods. Recently, CMR has been shown in a patient study to have a significant higher accuracy in the assessment of segmental myocardial function than echocardiography. ${ }^{4}$ Left ventricular function is directly correlated with mortality. ${ }^{15} \mathrm{CMR}$ derived data of myocardial function thus may offer a good surrogate to stratify patients who will benefit from TMLR.

With quantitative CMR we demonstrated improved regional and global myocardial functions of hypoperfused and remote myocardium after TMLR in a porcine model. These changes were paralleled by improved blood flow and lessened necrosis in the target myocardium. Recent publications regarding a porcine model of chronic ischemia have demonstrated improvement in microcirculation ${ }^{16}$ and regional 
contractility $^{17} 12$ weeks after TMLR. These studies further support our data. On the basis of our results, we recommend CMR for the assessment of regional myocardial function as a surrogate end point in upcoming clinical TMLR trials.

\section{References}

1. Schofield PM, Sharples LD, Caine N, Burns S, Tait S, Wistow M, et al. Transmyocardial laser revascularization in patients with refractory angina: a randomized controlled trial. Lancet. 1999;353:519-24.

2. Allen KB, Dowling RD, Fudge TL, Schoettle GP, Selinger SL, Gangahar DM, et al. Comparison of transmyocardial revascularization with medical therapy in patients with refractory angina. $N$ Engl $\mathrm{J} \mathrm{Med}$. 1999;341:1029-36.

3. Frazier OH, March RJ, Horvath KA. Transmyocardial revascularization with a carbon dioxide laser in patients with end-stage coronary artery disease. $N$ Engl J Med. 1999;341:1021-8.

4. Nagel E, Lehmkuhl HB, Bocksch W, Klein C, Vogel U, Frantz E, et al. Noninvasive diagnosis of ischemia-induced wall motion abnormalities with the use of high-dose dobutamine stress-MRI. Circulation. 1999;99:763-70.

5. Hautamaa PV, Dai XZ, Homans DC, Bache RJ. Vasomotor activity of moderately well-developed canine coronary collateral circulation. Am J Physiol. 1989;256(3 Pt 2):H890-7.

6. von Land CD, Rao SR, Reiber JH. Development of an improved centerline wall motion model. Comp Cardiol. 1991:687-90.

7. Wilke N, Simm C, Zhang J, Ellermann J, Ya X, Merkle H, et al. Contrast-enhanced first pass myocardial perfusion imaging: correlation between myocardial blood flow in dogs at rest and during hyperemia. Magn Reson Med. 1993;29:485-97.

8. Kramer CM, Lima JA, Reichek N, Ferrari VA, Llaneras MR, Palmon $\mathrm{LC}$, et al. Regional differences in function within noninfarcted myo- cardium during left ventricular remodeling. Circulation. 1993;88:127988.

9. Jaarsma W, Visser CA, Eenige van MJ, Res JC, Funke Kupper AJ, Verheugt FW, et al. Prognostic implications of regional hyperkinesia and remote asynergy of noninfarcted myocardium. Am J Cardiol. 1986;58:394-8.

10. Wyatt HL, Forrester JS, da Luz PL, Diamond GA, Chagrasulis R, Swan HJ. Functional abnormalities in nonoccluded regions of myocardium after experimental coronary occlusion. Am J Cardiol. 1976; 37:366-72.

11. Yamamoto N, Kohmoto T, Gu A, DeRosa C, Smith CR, Burkhoff D. Angiogenesis is enhanced in ischemic canine myocardium by transmyocardial laser revascularization. J Am Coll Cardiol. 1998;31: 1426-33.

12. Kohmoto T, DeRosa CM, Yamamoto N, Fisher PE, Failey P, Smith $\mathrm{CR}$, et al. Evidence of vascular growth associated with laser treatment of normal canine myocardium. Ann Thorac Surg. 1998;65:1360-7.

13. Saririan M, Eisenberg MJ. Myocardial laser revascularization for the treatment of end-stage coronary artery disease. $J$ Am Coll Cardiol. 2003;41:173-83.

14. Donovan CL, Landolfo KP, Lowe JE, Clements F, Coleman RB, Ryan T. Improvement in inducible ischemia during dobutamine stress echocardiography after transmyocardial laser revascularization in patients with refractory angina pectoris. J Am Coll Cardiol. 1997;30:607-12.

15. Longmore DB, Klipstein RH, Underwood SR, Firmin DN, Hounsfield GN, Watanabe M, et al. Dimensional accuracy of magnetic resonance in studies of the heart. Lancet. 1985;1:1360-2.

16. Lutter G, Martin J, Dern P, Sarai K, Olschewski M, von Samson P, et al. Evaluation of the indirect revascularization method after 3 months chronic myocardial ischemia. Eur J Cardiothorac Surg. 2000;18:3845 .

17. Horvath KA, Greene R, Belkind N, Kane B, McPherson DD, Fullerton DA. Left ventricular functional improvement after transmyocardial laser revascularization. Ann Thorac Surg. 1998;66:721-5.

\section{Online-www.aats.org}

Now you can get The Journal of Thoracic and Cardiovascular Surgery online. The Journal online brings you faster delivery time, easy searching of current and back issues, links to PubMed, AATS, WTSA, and other important sites, and more. Visit the Journal online today.

\section{Receive tables of contents by e-mail}

To receive the tables of contents by e-mail, sign up through our Web site at http://www.mosby.com/jtcvs

Choose E-mail Notification

Simply type your e-mail address in the box and click the Subscribe button. Alternatively, you may send an e-mail message to majordomo@mosby.com. Leave the subject line blank and type the following as the body of your message: subscribe jtcvs_toc You will receive an e-mail to confirm that you have been added to the mailing list.

Note that TOC e-mails will be sent out when a new issue is posted to the Web site. 